\title{
Relationships of Family Food Environment with Food and Nutrition Literacy in Chinese School-Age Children
}

Niuniu Li

Peking University Health Science Centre

Xiao Su

Peking University Health Science Centre

Tan Liu

Peking University Health Science Centre

Jing Sun

Peking University Health Science Centre

Wenli Zhu ( $\square$ zhuwenli@bjmu.edu.cn)

\section{Research article}

Keywords: Family food environment, food and nutrition literacy, school-age children, caregiver

Posted Date: June 3rd, 2020

DOI: https://doi.org/10.21203/rs.3.rs-32377/v1

License: @ (i) This work is licensed under a Creative Commons Attribution 4.0 International License. Read Full License 


\section{Abstract}

Background Eating behavior is influenced by multiple factors and understanding the interplay of these factors is necessary to promote children's healthy food choices. This study investigated the relations of family food environment (FFE) factors with food and nutrition literacy (FNL) in Chinese school-age children.

Methods A total of 605 children aged $7 \sim 13$ years from grade 1 to 5 , and their caregivers participated in the cross-sectional study in Beijing of China during April 2019. The FFE was assessed by the validated Family Food Environment Questionnaire for Chinese School-age Children (FFEQ-SC). For the children of grade 3 to $5(n=260)$, the FNL, including cognitive and skill domains, was assessed by Food and Nutrition Literacy Questionnaire for Chinese School-age Children (FNLQ-SC). Both FFEQ-SC and FNLQ-SC were developed firstly for Chinese school-age children and had good reliability. The anthropometric data (height and weight) was derived from local health information management system for primary schools.

Results Overall, $68.9 \%$ of the children's families had higher level of FFE. The total FNL score of 260 children from grade $3-5$ was $63.23 \pm 10.32$. Comparison of children's FNL score among different levels of FFE showed the children with higher level of FFE, especially higher level of caregiver's educational degree and FNL, were more likely to have significant higher FNL scores $(P<0.05)$. The multivariate analysis showed the children's total FNL score was significantly related with family caregiver $(\beta=-0.123, P=0.04)$ and caregiver's nutritional literacy $(\beta=0.210, P=0.002)$. Furthermore, the children with higher level of caregiver's nutritional knowledge were less likely to be overweight or obesity $(\mathrm{OR}=0.043, P=0.04)$.

Conclusions and Implications: Family food environment, especially caregivers' FNL, were significantly related with children's FNL, even the risk of overweight. These findings highlight the importance of targeting nutritional knowledge of family caregivers to facilitate the children's FNL to maintain good health.

\section{Background}

Globally, there are 1.8 billion children and adolescents ages 5-19 years. A comprehensive and integrated overview showed that the remarkable nutritional transition in adolescent health occurred globally, the prevalence of overweight was $18 \%$ in 2016 , an increase of 176.9 million compared with 1990 , and prevalence of anemia was $24 \%$ in 2016, an increase of 74.2 million compared with 1990 [2]. Correspondingly, the food choices and dietary quality in childhood, which affected the lifelong risk of nutrition-related diseases [17;32], remained poor over the world. American National Health and Nutrition Examination Survey (NHANES) in 2015-2016 showed 56.1\% (95\% Cl: 51.4\%-60.7\%) of youth aged 2 to 19 years had poor quality diets [18]. Latent class analysis of the China Health and Nutrition Survey (CHNS) data revealed four types of food preferences in 697 adolescents aged 12 to 17 years, including varied diet (37.09\%), avoiding vegetables (19.69\%), low appetite (7.56\%) and healthy diet (35.66\%) [23]. The Global School-Based Student Health Survey (GSHS) in 2019 showed roughly half of the countries reported that $10 \%-30 \%$ of $13-15$ years old students did not eat any fruit at all, and a quarter reported that $10 \%-30 \%$ of students did not eat any vegetables at all; Nearly $70 \%$ of countries reported that at least half of their students eat fast food on a weekly basis; all countries found that one out of five students consumed carbonated soft drinks at least once a day [9]. Recent reports suggested unhealthy eating behavior in childhood may have reached plateau and even decreased slightly from 2000 in developed countries, while in many developing and transition countries including China, the problems have become far more complex and intractable [4].

Following an ecological model, food choices and eating behavior depend on the interaction of different environmental factors and personal characteristics, such as genetics, sociodemographic characteristics, nutrition related knowledge and skill [20]. At individual level, food and nutrition literacy is generally defined as the individual capacity to obtain, process, and understand nutrition information and skills needed to make appropriate nutrition decisions and maintain a good diet and health, which is one way to understand the reasons behind the nutrition-related problems and behaviors among children and adolescents [1]. A systematic review showed that food literacy may play a role in shaping adolescent's dietary intake, in addition, findings suggest that food skills and behaviors learned in adolescence are sustained later in life [26]. There are many factors that might relate to the individual food and nutrition literacy, such as nutrition education, food environment and other adjustable variables [3;8].

Eating behavior is highly complex and influenced by multiple factors across different contexts, which has been conceptualized as a function of the social and physical environment. The child's ecological niche includes family and peers, which are both influenced by community, society, media, and food offering [5], these different environmental factors are defined as food environment. Considering most of children's eating behaviors occur at and around home, so the potential impact of family food environment on children's eating behavior and diet quality is particularly relevant. Young children depend on their families to support their wellbeing and promote positive development, including eating behaviors. The family food environment is the most fundamental context in which children's eating behaviors are socialized and food preferences are formed. A systematic review indicated family environmental factors, which were consistently and positively associated with children's healthy food consumption, were household food availability, nutritional knowledge of family or caregivers and family income [21]. The Cochrane living systematic review assessed the effectiveness of 78 eligible intervention trials till August 2019 , the results showed that parents' child-feeding practice may lead to small increases in fruit and vegetable consumption in children, with very low-quality evidence, and future research should adopt more rigorous methods to advance the field [15].

Both individual food and nutrition literacy and contextual food environment are important factors influencing children's eating behaviors; but their interaction remained unclear. It was hypothesized that the food environment, especially the caregivers' nutritional knowledge and skill, may help children develop the food and nutrition literacy, then improve their food choice and dietary quality. Therefore, this study investigated the relationship of FFE withFNLin Chinese schoolage children, to provide evidence for further intervention.

\section{Methods}

\section{The family food environment questionnaire for Chinese school-age children}

Page 2/15 
The study firstly developed and validated the FFEQ-SC. The conceptual framework and dimensions of FFEQ-SC were preliminarily constructed based on literature review and evaluated by food and nutrition experts in the study steering group.

The framework for the Analysis Grid for Elements Linked to Obesity (ANGELO) process was first developed for use as a practical tool for categorizing and scanning the environment for potential environmental barriers to healthy eating and physical activity [24]. The basic framework is a $2 \times 4$ grid which divides obesogenic environments in two sizes of environment - micro and macro, and four types of environment - physical, economic, policy and sociocultural. Referring to ANGELO framework and other assessment instruments, the FFEQ-SC was developed including six dimensions: 1) Family sociodemographic characteristics, including family structure (member number), family economic status, caregivers and their educational level and so on. The family economic status was assessed using adjusted "The Family Affluence Scale (FAS)", which was a six-item scale used in Health Behavior in School-aged Children (HBSC), a WHO collaborative cross-national study [26]. Considering the Chinese family situation, three items were remained, like "Does your family own a car, van or truck?"; "Do you have your own bedroom for yourself?"; "How many times did your family travel for a holiday/vacation last year?". 2) Caregiver's food and nutrition literacy, including nutritional knowledge and skill (food and nutrients, dietary guideline, food labelling and food portion), modeling and encouragement practices, discussing nutrition information with children, and so on. 3) Family feeding patterns, including permission (I permit my child to eat what he/she wants.), restriction (I have to be sure that my child does not eat too many foods high in sugar, fat and salt.), enforcement patterns (If my child says "I am not hungry" I try to get him/her to eat anyway.) and so on. 4) Family eating rules, including focusing on dinner (No meals while watching TV/DVDs), food limitation (I limit my child to eat foods high in sugar, fat and salt.) and food preparation (My child must help prepare food and do the dishes). 5) Family meal practices, including location, length, frequency and members present of family meals. 6) Family food availability, including healthy foods (fruits and vegetables, dairy products and whole grain) and unhealthy foods high in sugar, fat and salt.

Secondly, a cross-sectional survey was conducted in 599 Chinese school-age ( 7 13 years) children's parents, to analyze the reliability and validity of FFEQSC. The preliminary questionnaire had 54 items. Finally, 47 items were included by the exclusion criteria as item discrimination less than 0.1 , coefficient of difficulty more than 0.15 and less than $\mathbf{0 . 8 5}$, factor loads less than 0.4 , and factor loading coefficients were similar in 2 or more than 2 factors. The overall FFEQ-SC questionnaire had high internal consistency (Cronbach's $a=0.78$, split-half reliability $=0.84$ ). The exploratory factor analysis extracted 15 factors which were included in the conceptual framework, and cumulative contribution of variance accounted to $62.33 \%$. The Pearson correlation coefficients between dimensions and total questionnaire were from 0.33 to 0.76 . The results of construct validity were $\chi^{2} / \mathrm{df}=1.97$, goodness of fit index $(\mathrm{GFI})=0.88$, adjusted goodness of fit $(\mathrm{AGFI})=0.85$, normed fit index $(\mathrm{NFI})=0.86$, incremental fit index $(\mathrm{IFI})=0.92$, comparative fit index $(\mathrm{CFI})=0.92$, root mean square residual $(\mathrm{RMR})=0.03$, and root mean square error of approximation $(\mathrm{RMSEA})=0.04(P>0.05)$. The results showed the FFEQ-SC had good reliability, and it could potentially be a useful instrument for assessing FFE for Chinese school-age children.

\section{The food and nutrition literacy questionnaire for Chinese school-age children}

Till now there are no FNL assessment instruments for Chinese children. The study developed and validated the FNLQ-SC.

The conceptual framework and dimensions of FNLQ-SC were preliminarily constructed based on literature review and experts interview, considering the cognitive level and dietary behavior problems in school-age children. In this study FNL is defined as "collection of inter-related knowledge, skills and behaviors required to plan, manage, select, prepare and eat foods to meet needs and determine food intake". A two-stage electronically distributed Delphi consultation study was conducted to determine the dimension and core components of FNLQ-SC. Finally, 19 core components of FNLQ-SC were determined, including five dimensions of food and nutrition related knowledge and understanding (cognitive domain), the ability of access, selection, preparing of food and healthy eating (skill domain), as well as three levels of functional, interactive and critical literacy. The final questionnaire included 50 questions.

Secondly, a cross-sectional survey was conducted in 2452 Chinese children aged 10-15 years, to analyze the reliability and validity of FNLQ-SC. The results showed the overall FNLQ-SC questionnaire had high internal consistency (Cronbach's a $=0.698$ ). Regarding the five dimensions (knowledge and understanding, access and planning of food, selecting food, preparing food, eating), Cronbach's a coefficient was $0.452,0.300,0.244,0.148,0.436$, respectively. The Kaiser-Meyer-Olkin (KMO) test showed sampling adequacy (KMO = 0.738), and Bartlett's test confirmed factor analysis was appropriate $(P$ $<0.001$ ). The exploratory factor analysis (EFA) of skill components extracted 5 factors (selecting and eating, access and preparation, food label and measurement, picky eating, snacks) with eigenvalue more than 1, and cumulative contribution of variance accounted to $50.60 \%$. The commonality was more than 0.20 for all components. The Pearson correlation coefficients among different dimensions were ranged $0.152 \sim 0.400$, and correlation coefficients between dimensions and total questionnaire were from 0.370 to 0.877 , especially the dimension of knowledge and understanding, selecting food, and eating, whose coefficients were more than 0.6 , that showed strong correlation with total questionnaire. The results showed the FNLQ-SC had good reliability, and it could potentially be a useful instrument for assessing FNL for Chinese school-age children.

\section{Participants and data collection}

A cross-sectional survey was conducted in a primary school in Beijing of China using convenient sampling during April 2019. A total of 605 school-age children from grade 1 to 5 and their caregivers were included in the study. For all participant children $(n=605)$, the FFE was assessed by developed selfadministered FFEQ-SC, which was filled out by children's caregiver.

Considering the differences of cognition, reading and writing literacy between junior and senior students, the FNL should be assessed by different instruments. Based on these, just for the senior children of grade 3 to $5(n=260)$, the FNL was assessed by self-administered FFEQ-SC, which was developed and validated for students of grade $3-8$, not for junior primary students (grade 1-2).

The children's anthropometric data (height, weight) were derived from "Beijing health information management system for primary and secondary schools", which was measured in April 2019. And the BMI $\left(\mathrm{kg} / \mathrm{m}^{2}\right)$ was calculated and defined according to Chinese standards of "Screening for overweight and obesity 
among school-age children and adolescents (WS/T 586-2018)" and "Screening standard for malnutrition of school-age children and adolescents (WS/T 456-2014)".

The study protocol was approved by the Peking University Institutional Review Board (Beijing, China) and informed written consent was obtained from children and their caregivers.

\section{Statistical analysis}

Except some items of family sociodemographic characteristics (family member number, caregiver), which relations with children's food choice remained inconsistent, other items were scored, and the total score of FFEQ-SC was 94, including 18 of family sociodemographic characteristics, 20 of caregiver's FNL, 14 of family feeding patterns, 18 of family eating rules, 8 of family meal practices, and 16 of family food availability. Considering the scores were positively related with better/healthier performance theoretically, so the six dimensions was defined as two levels of high/good/healthy ( $\geq P_{60}$ of total score) and low/poor/unhealthy ( $<P_{60}$ of total score). It was noteworthy that the higher score of family feeding patterns was associated with more freedom of children's food choice, and then different feeding patterns were defined as permission ( $\geq P_{60}$ of total score), restriction $\left(P_{40} \sim P_{60}\right)$ and enforcement $\left(<P_{40}\right)$ patterns.

The total scores of FNLQ-SC were 92 in grade 3-4 and 98 in grade 5 respectively, which was converted in a centesimal measure for further statistical analysis.

The relations of family food environment with FNL of children were analyzed by $\mathrm{t} / \mathrm{F}$ test and LSD adjustment $(P<0.05)$, correlation coefficient and multivariate linear regression analysis $(P<0.05)$.

\section{Results}

\section{Characteristics of the participant children and their family food environment}

Among all 605 children of grade 1-5, there were 303 (50.1\%) boys and 302 (49.9\%) girls, aged 7 13 years. And $54.7 \%$ of the children were "only child". Overall, $68.9 \%$ of children's families had higher level of FFE. Most of the family caregivers were their mother (71.4\%) or father ( $27.1 \%)$. More than half (59.5\%) of the caregiver's educational level was junior college or higher, and $69.3 \%$ of those had high level of FNL. More families restricted (61.3\%) or enforced (20.2\%) their children to eat or not to eat certain foods, compared with permission feeding pattern (18.5\%). Most of the families had eating rules (65.3\%) and good meal practices (68.9\%). $78.2 \%$ of the families supplied their children more healthy foods than unhealthy foods.

Among 260 children in subgroup, the percentage of grade 3, 4, 5 were $22.3 \%, 35.0 \%$ and $42.7 \%$ respectively, aged from 9 to 13 years. The prevalence of overweight and obesity were $16.9 \%$ and $20.8 \%$ respectively. Nearly half of children (48.8\%) were "only child". Overall, $61.5 \%$ of children's families had high level of FFE. Most of the family caregivers were their mother $(69.2 \%)$ or father $(28.8 \%)$, and $68.8 \%$ of the caregivers had high level of FNL. More families adopt restriction (61.5\%) and enforcement (24.2\%) feeding patterns. Most of the families had eating rules (61.5\%) and good meal practices (65.0\%). $69.6 \%$ of the families supplied their children more healthy foods than unhealthy foods. The characteristics of the children and their families are shown in Table 1. 
Table 1

Characteristics of the participant children and their family food environment $\mathrm{n}(\%)$

\begin{tabular}{|c|c|c|}
\hline Characteristics & Total $(n=605)$ & Subgroup $(n=260)$ \\
\hline \multicolumn{3}{|l|}{ Gender } \\
\hline Boys & $303(50.1)$ & $125(48.1)$ \\
\hline Girls & $302(49.9)$ & $135(51.9)$ \\
\hline \multicolumn{3}{|l|}{ Age (years) } \\
\hline $7 \sim 8$ & $304(50.2)$ & - \\
\hline $9 \sim 10$ & $169(27.9)$ & $133(51.2)$ \\
\hline $11 \sim 13$ & $132(21.8)$ & $127(48.8)$ \\
\hline \multicolumn{3}{|l|}{ Grade } \\
\hline Junior (1 2) & $308(50.9)$ & - \\
\hline Senior (3 5) & $297(49.1)$ & $260(100.0)$ \\
\hline \multicolumn{3}{|l|}{ Weight status (BMI) } \\
\hline Wasted & $31(5.1)$ & $11(4.2)$ \\
\hline Normal & $331(54.7)$ & $151(58.1)$ \\
\hline Overweight & $90(14.9)$ & $44(16.9)$ \\
\hline Obesity & $153(25.3)$ & $54(20.8)$ \\
\hline \multicolumn{3}{|l|}{ Only child } \\
\hline Yes & $331(54.7)$ & $127(48.8)$ \\
\hline No & $274(45.3)$ & $133(51.2)$ \\
\hline \multicolumn{3}{|c|}{ Family size (member number) } \\
\hline$\leq 3$ & $194(32.1)$ & $79(30.4)$ \\
\hline 4 & $179(29.6)$ & $98(37.7)$ \\
\hline$\geq 5$ & $232(38.3)$ & $83(31.9)$ \\
\hline \multicolumn{3}{|c|}{ Family economic status } \\
\hline Poor $(\leq 2)$ & $72(11.9)$ & $25(9.6)$ \\
\hline Medium (3-5) & $325(53.7)$ & $138(53.1)$ \\
\hline Affluent (6-7) & $208(34.4)$ & $97(37.3)$ \\
\hline \multicolumn{3}{|l|}{ Caregiver } \\
\hline Mother & $432(71.4)$ & $180(69.2)$ \\
\hline Father & $164(27.1)$ & $75(28.8)$ \\
\hline Others & $9(1.5)$ & $5(1.9)$ \\
\hline \multicolumn{3}{|c|}{ Caregiver's educational level } \\
\hline$\leq$ High school & $245(40.5)$ & $138(53.1)$ \\
\hline$\geq$ Junior college & $360(59.5)$ & $122(46.9)$ \\
\hline \multicolumn{3}{|c|}{ Caregiver's food and nutrition literacy } \\
\hline High ( $\geq 12.0)$ & $419(69.3)$ & $179(68.8)$ \\
\hline Low $(<12.0)$ & $186(30.7)$ & $81(31.2)$ \\
\hline \multicolumn{3}{|l|}{ Family feeding patterns } \\
\hline Permission ( $\geq 8.4$ ) & $112(18.5)$ & $37(14.2)$ \\
\hline Restriction $(5.6 \sim 8.4)$ & $371(61.3)$ & $160(61.5)$ \\
\hline Enforcement $(<5.6)$ & $122(20.2)$ & $63(24.2)$ \\
\hline
\end{tabular}




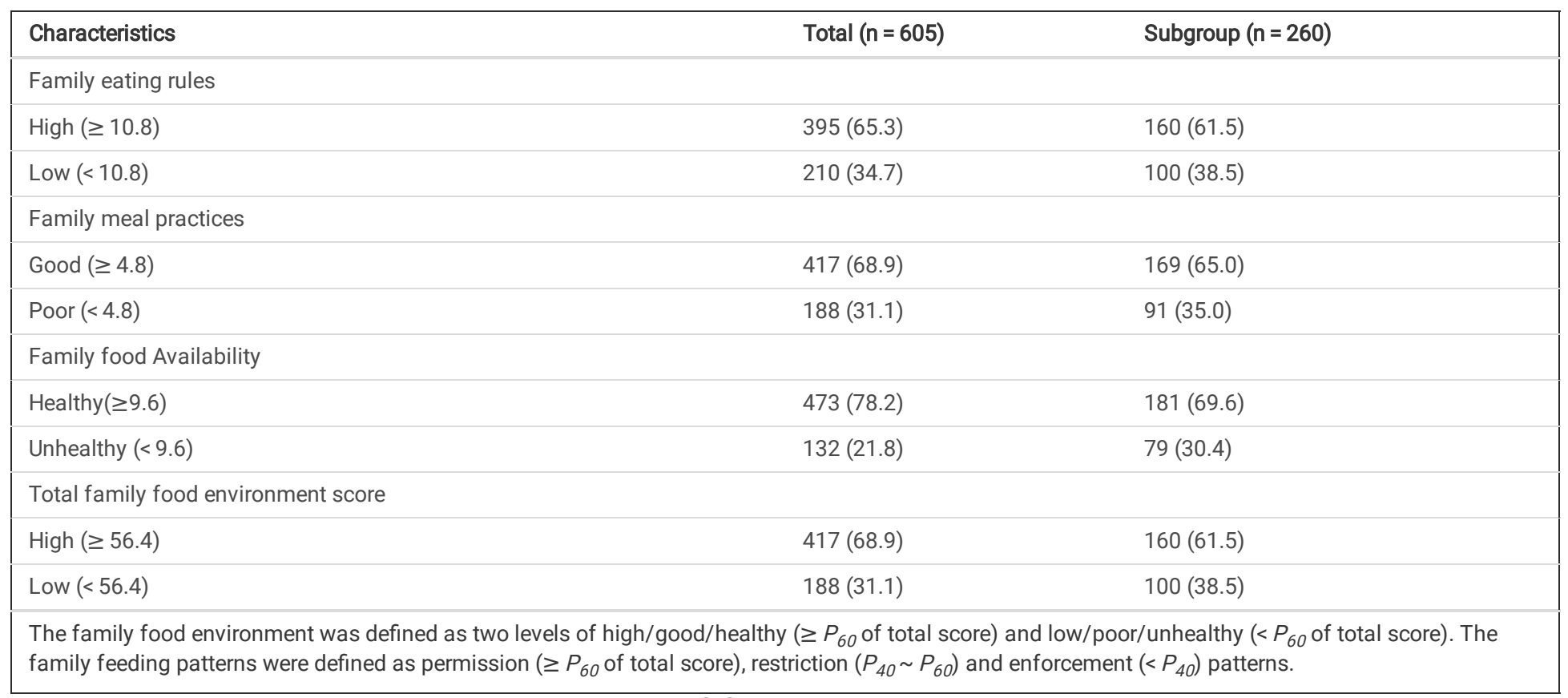

\section{Family sociodemographic distribution of food and nutrition literacy in children}

The total FNL score of 260 children in grade $3-5$ was $63.23 \pm 10.32$ ranged from 30.36 to 89.93 (centesimal measure). As shown in Table 2 , the girls had higher FNL score than boys, especially the ability to select food $(P=0.04)$. The FNLQ-SC score increased by grade and age, the abilities of access and planning of food, selecting food in the 5 th grader were much higher than those of the 3rd grader $(P=0.001)$. 
Table 2

Sociodemographic predictors of food and nutrition literacy in children (mean \pm SD)

\begin{tabular}{|c|c|c|c|c|c|c|c|}
\hline $\begin{array}{l}\text { Sociodemographic } \\
\text { characteristics }\end{array}$ & $n$ & $\begin{array}{l}\text { Knowledge and } \\
\text { understanding }\end{array}$ & $\begin{array}{l}\text { Access and planning of } \\
\text { food }\end{array}$ & $\begin{array}{l}\text { Selecting } \\
\text { food }\end{array}$ & $\begin{array}{l}\text { Preparing } \\
\text { food }\end{array}$ & Eating & Total \\
\hline Total & 260 & $11.1 \pm 2.7$ & $2.8 \pm 0.8$ & $12.3 \pm 3.1$ & $6.2 \pm 1.6$ & $30.8 \pm 5.6$ & $63.2 \pm 10.3$ \\
\hline \multicolumn{8}{|l|}{ Gender } \\
\hline Boys & 125 & $10.8 \pm 2.7$ & $2.8 \pm 0.8$ & $11.9 \pm 3.1^{\mathrm{a}}$ & $6.4 \pm 1.6$ & $30.4 \pm 5.6$ & $62.3 \pm 10.4$ \\
\hline Girls & 135 & $11.3 \pm 2.6$ & $2.9 \pm 0.8$ & $12.7 \pm 3.1^{b}$ & $6.1 \pm 1.6$ & $31.2 \pm 5.7$ & $64.1 \pm 10.2$ \\
\hline$P$ & & 0.13 & 0.23 & $0.04 *$ & 0.09 & 0.27 & 0.15 \\
\hline \multicolumn{8}{|l|}{ Age (years) } \\
\hline $9 \sim 10$ & 133 & $10.9 \pm 2.8$ & $2.8 \pm 0.9^{a}$ & $11.8 \pm 2.8$ & $6.2 \pm 1.5$ & $30.7 \pm 5.8$ & $62.4 \pm 9.8$ \\
\hline $11 \sim 13$ & 127 & $11.3 \pm 2.5$ & $2.9 \pm 0.7^{b}$ & $12.8 \pm 3.3$ & $6.2 \pm 1.7$ & $30.9 \pm 5.5$ & $64.1 \pm 10.8$ \\
\hline$P$ & & 0.13 & $0.001 *$ & 0.14 & 0.66 & 0.53 & 0.17 \\
\hline \multicolumn{8}{|l|}{ Grade } \\
\hline 3 & 58 & $10.5 \pm 2.8$ & $2.5 \pm 0.9^{a}$ & $11.2 \pm 2.9^{a}$ & $6.1 \pm 1.5$ & $30.4 \pm 6.4$ & $60.6 \pm 11.2$ \\
\hline 4 & 91 & $11.3 \pm 2.6$ & $3.0 \pm 0.8^{b}$ & $12.4 \pm 2.6$ & $6.3 \pm 1.6$ & $31.4 \pm 5.3$ & $64.4 \pm 8.4$ \\
\hline 5 & 111 & $11.3 \pm 2.6$ & $2.9 \pm 0.7^{b}$ & $12.8 \pm 3.4^{b}$ & $6.2 \pm 1.7$ & $30.6 \pm 6.4$ & $63.7 \pm 11.1$ \\
\hline$P$ & & 0.17 & $<0.001 *$ & $0.006 *$ & 0.74 & 0.45 & 0.08 \\
\hline \multicolumn{8}{|l|}{ Only child } \\
\hline Yes & 127 & $11.3 \pm 2.7$ & $2.9 \pm 0.7$ & $12.7 \pm 2.9^{\mathrm{a}}$ & $6.3 \pm 1.7$ & $\begin{array}{l}31.6 \pm \\
5.3^{a}\end{array}$ & $\begin{array}{l}64.9 \pm \\
10.1^{a}\end{array}$ \\
\hline No & 133 & $10.8 \pm 2.6$ & $2.8 \pm 0.8$ & $11.9 \pm 3.2^{b}$ & $6.1 \pm 1.7$ & $\begin{array}{l}30.1 \pm \\
5.9^{\mathrm{b}}\end{array}$ & $\begin{array}{l}61.6 \pm \\
10.3^{b}\end{array}$ \\
\hline$P$ & & 0.11 & 0.14 & $0.03^{*}$ & 0.35 & $0.03 *$ & $0.01 *$ \\
\hline \multicolumn{8}{|c|}{ Family size (member number) } \\
\hline$\leq 3$ & 79 & $11.2 \pm 2.7$ & $2.9 \pm 0.8$ & $12.6 \pm 3.0$ & $6.3 \pm 1.7$ & $31.5 \pm 5.9$ & $64.5 \pm 10.4$ \\
\hline 4 & 98 & $11.0 \pm 2.7$ & $2.7 \pm 0.8$ & $12.1 \pm 3.1$ & $6.2 \pm 1.6$ & $30.4 \pm 5.6$ & $62.4 \pm 10.4$ \\
\hline$\geq 5$ & 83 & $11.0 \pm 2.7$ & $2.9 \pm 0.7$ & $12.2 \pm 3.2$ & $6.2 \pm 1.6$ & $30.8 \pm 5.5$ & $63.0 \pm 10.2$ \\
\hline$P$ & & 0.86 & 0.28 & 0.51 & 0.77 & 0.44 & 0.38 \\
\hline \multicolumn{8}{|c|}{ Family economic status } \\
\hline Poor $(\leq 2)$ & 25 & $11.3 \pm 3.0$ & $2.9 \pm 0.7$ & $11.8 \pm 2.7$ & $6.2 \pm 1.5$ & $28.4 \pm 5.0$ & $60.6 \pm 9.5$ \\
\hline Medium (3-5) & 138 & $11.0 \pm 2.7$ & $2.8 \pm 0.8$ & $12.3 \pm 3.3$ & $6.0 \pm 1.5$ & $31.0 \pm 5.3$ & $63.1 \pm 10.3$ \\
\hline Affluent (6-7) & 97 & $11.0 \pm 2.6$ & $2.9 \pm 0.7$ & $11.4 \pm 2.9$ & $6.5 \pm 1.8$ & $31.3 \pm 6.4$ & $64.2 \pm 10.6$ \\
\hline$P$ & & 0.91 & 0.54 & 0.69 & 0.08 & 0.07 & 0.29 \\
\hline \multicolumn{8}{|l|}{ Caregiver } \\
\hline Mother & 180 & $11.0 \pm 2.7$ & $2.8 \pm 0.8$ & $12.1 \pm 2.9$ & $6.2 \pm 1.6$ & $\begin{array}{l}30.4 \pm \\
5.7^{\mathrm{a}}\end{array}$ & $\begin{array}{l}62.4 \pm \\
10.3^{a}\end{array}$ \\
\hline Father & 75 & $11.3 \pm 2.6$ & $2.9 \pm 0.8$ & $12.8 \pm 3.4$ & $6.3 \pm 1.6$ & $\begin{array}{l}32.2 \pm \\
5.2^{b}\end{array}$ & $65.4 \pm 9.9^{b}$ \\
\hline$P$ & & 0.42 & 0.34 & 0.10 & 0.50 & $0.02 *$ & $0.03^{*}$ \\
\hline \multicolumn{8}{|c|}{ Caregiver's educational level } \\
\hline$\leq$ High school & 138 & $10.3 \pm 2.7$ & $2.8 \pm 0.8$ & $11.8 \pm 3.3^{\mathrm{a}}$ & $6.0 \pm 1.7^{a}$ & $\begin{array}{l}30.0 \pm \\
6.0^{\mathrm{a}}\end{array}$ & $\begin{array}{l}61.4 \pm \\
10.7^{a}\end{array}$ \\
\hline
\end{tabular}

${ }^{*} P<0.05$, Statistical test used chi-square and LSD. Different superscript characters $(\mathrm{a}, \mathrm{b})$ mean statistical difference among groups $(P \otimes 0.05)$. 


\begin{tabular}{|c|c|c|c|c|c|c|c|}
\hline $\begin{array}{l}\text { Sociodemographic } \\
\text { characteristics }\end{array}$ & $\mathrm{n}$ & $\begin{array}{l}\text { Knowledge and } \\
\text { understanding }\end{array}$ & $\begin{array}{l}\text { Access and planning of } \\
\text { food }\end{array}$ & $\begin{array}{l}\text { Selecting } \\
\text { food }\end{array}$ & $\begin{array}{l}\text { Preparing } \\
\text { food }\end{array}$ & Eating & Total \\
\hline$\geq$ Junior college & 122 & $11.3 \pm 2.6$ & $2.9 \pm 0.8$ & $12.8 \pm 2.8^{b}$ & $6.5 \pm 1.6^{b}$ & $\begin{array}{l}31.8 \pm \\
5.1^{\mathrm{b}}\end{array}$ & $65.3 \pm 9.6^{b}$ \\
\hline$P$ & & 0.13 & 0.64 & $0.008 *$ & $0.03^{*}$ & $0.009 *$ & $0.003^{*}$ \\
\hline
\end{tabular}

Not only above individual characteristics, but also the family sociodemographic characteristics, including the number of children in the family, the caregiver and their educational level, were significantly related with children's FNL. The "only child" had higher FNL score $(64.9 \pm 10.1$ vs $61.6 \pm 10.3, P=0.01)$, especially the ability of selecting and eating food $(P<0.05)$. Furthermore, the children cared by their father dominantly had higher total FNL compared with those cared by mother $(65.4 \pm 9.9$ vs $62.4 \pm 10.3, P=0.01)$. Also the caregiver's educational level was positively associated with children's FNL $(P=0.003)$, especially in dimensions of selecting, preparing and eating food $(P<0.05)$. As shown in Table 2.

\section{Relationship of family physical and sociocultural food environment with food and nutrition literacy in children}

As shown in Table 3, comparison of the FNL score in children between two FFE levels showed the children with high level of FFE, especially high level of caregiver's FNL, had significant higher FNL scores, including total score and all domains of cognitive and skill $(P<0.05)$. Furthermore, the children with high level of family eating rules were more likely to have higher FNL scores, especially in dimensions of knowledge and understanding, the ability of access and planning of food, and eating $(P<0.05)$. If the family supplied the children more healthy foods compared with unhealthy foods, the children had much higher score of food and nutrition related knowledge and understanding $(P<0.05)$. 
Table 3

Relations of family physical and sociocultural food environment with food and nutrition literacy in children (mean \pm SD)

\begin{tabular}{|c|c|c|c|c|c|c|c|}
\hline $\begin{array}{l}\text { Family physical and sociocultural food } \\
\text { environment level }\end{array}$ & $\mathrm{n}$ & $\begin{array}{l}\text { Knowledge and } \\
\text { Understanding }\end{array}$ & $\begin{array}{l}\text { Access and planning } \\
\text { of food }\end{array}$ & $\begin{array}{l}\text { Selecting } \\
\text { food }\end{array}$ & $\begin{array}{l}\text { Preparing } \\
\text { food }\end{array}$ & Eating & Total \\
\hline \multicolumn{8}{|l|}{ Total } \\
\hline High ( $\geq 56.4)$ & 160 & $11.5 \pm 2.6$ & $2.9 \pm 0.7$ & $12.7 \pm 3.0$ & $6.4 \pm 1.6$ & $\begin{array}{l}31.9 \pm \\
5 .\end{array}$ & $\begin{array}{l}65.4 \pm \\
10.0\end{array}$ \\
\hline Low $(<56.4)$ & 100 & $10.3 \pm 2.6$ & $2.7 \pm 0.9$ & $11.7 \pm 3.1$ & $6.0 \pm 1.7$ & $\begin{array}{l}29.1 \pm \\
5.1\end{array}$ & $\begin{array}{l}59.7 \pm \\
10.0\end{array}$ \\
\hline$P$ & & $<0.001^{*}$ & $0.02 *$ & $0.01 *$ & $0.05^{*}$ & $\dot{0.001 *}$ & ¿.001* \\
\hline \multicolumn{8}{|l|}{ Caregiver's food and nutrition literacy } \\
\hline High $(\geq 12.0)$ & 179 & $11.5 \pm 2.7$ & $2.9 \pm 0.7$ & $12.7 \pm 3.1$ & $6.4 \pm 1.6$ & $\begin{array}{l}31.5 \pm \\
5.8\end{array}$ & $\begin{array}{l}65.0 \pm \\
10.3\end{array}$ \\
\hline Low $(<12.0)$ & 81 & $10.1 \pm 2.4$ & $2.7 \pm 0.8$ & $11.4 \pm 2.8$ & $5.9 \pm 1.6$ & $\begin{array}{l}29.4 \pm \\
5.1\end{array}$ & $\begin{array}{l}59.4 \pm \\
9.4\end{array}$ \\
\hline$P$ & & $<0.001 *$ & $0.01 *$ & $0.001^{*}$ & $0.03^{*}$ & $0.007^{*}$ & $\hat{0.001 *}$ \\
\hline \multicolumn{8}{|l|}{ Family feeding patterns } \\
\hline Permission ( $\geq 8.4$ ) & 37 & $10.7 \pm 3.0$ & $2.8 \pm 0.9$ & $12.1 \pm 3.0$ & $6.5 \pm 1.6$ & $\begin{array}{l}31.5 \pm \\
5.2\end{array}$ & $\begin{array}{l}63.6 \pm \\
9.8\end{array}$ \\
\hline Restriction $(5.6 \sim 8.4)$ & 160 & $11.2 \pm 2.6$ & $2.8 \pm 0.8$ & $12.4 \pm 3.0$ & $6.1 \pm 1.6$ & $\begin{array}{l}30.8 \pm \\
5.8\end{array}$ & $\begin{array}{l}63.2 \pm \\
10.2\end{array}$ \\
\hline Enforcement $(<5.6)$ & 63 & $11.0 \pm 2.6$ & $2.9 \pm 0.7$ & $12.1 \pm 3.3$ & $6.4 \pm 1.7$ & $\begin{array}{l}30.6 \pm \\
5.6\end{array}$ & $\begin{array}{l}63.0 \pm \\
11.0\end{array}$ \\
\hline$P$ & & 0.66 & 0.70 & 0.75 & 0.24 & 0.73 & 0.96 \\
\hline \multicolumn{8}{|l|}{ Family eating rules } \\
\hline High $(\geq 10.8)$ & 160 & $11.4 \pm 2.7$ & $2.9 \pm 0.7$ & $12.6 \pm 3.0$ & $6.2 \pm 1.6$ & $\begin{array}{l}31.7 \pm \\
5.8\end{array}$ & $\begin{array}{l}64.8 \pm \\
10.3\end{array}$ \\
\hline Low $(<10.8)$ & 100 & $10.5 \pm 2.6$ & $2.7 \pm 0.8$ & $11.8 \pm 3.2$ & $6.3 \pm 1.6$ & $\begin{array}{l}29.5 \pm \\
5.1\end{array}$ & $\begin{array}{l}60.7 \pm \\
9.8\end{array}$ \\
\hline$P$ & & $0.007^{*}$ & $0.003^{*}$ & 0.05 & 0.86 & $0.002 *$ & $0.002 *$ \\
\hline \multicolumn{8}{|l|}{ Family meal practices } \\
\hline Good ( $\geq 4.8)$ & 169 & $10.9 \pm 2.8$ & $2.8 \pm 0.8$ & $12.2 \pm 3.1$ & $6.1 \pm 1.5$ & $\begin{array}{l}30.7 \pm \\
5.6\end{array}$ & $\begin{array}{l}62.7 \pm \\
10.3\end{array}$ \\
\hline Poor (<4.8) & 91 & $11.4 \pm 2.5$ & $2.8 \pm 0.8$ & $12.4 \pm 3.0$ & $6.4 \pm 1.8$ & $\begin{array}{l}31.1 \pm \\
5.7\end{array}$ & $\begin{array}{l}64.2 \pm \\
10.4\end{array}$ \\
\hline$P$ & & 0.09 & 0.90 & 0.60 & 0.25 & 0.57 & 0.28 \\
\hline \multicolumn{8}{|l|}{ Family food availability } \\
\hline Healthy $(\geq 9.6)$ & 181 & $11.3 \pm 2.6$ & $2.9 \pm 0.7$ & $12.4 \pm 3.2$ & $6.3 \pm 1.6$ & $\begin{array}{l}31.2 \pm \\
5.6\end{array}$ & $\begin{array}{l}64.0 \pm \\
10.5\end{array}$ \\
\hline Unhealthy $(<9.6)$ & 79 & $10.6 \pm 2.8$ & $2.8 \pm 0.9$ & $6.3 \pm 1.6$ & $6.0 \pm 1.8$ & $\begin{array}{l}30.1 \pm \\
5.6\end{array}$ & $\begin{array}{l}61.4 \pm \\
9.8\end{array}$ \\
\hline$P$ & & $0.04^{*}$ & 0.46 & 0.44 & 0.13 & 0.14 & 0.06 \\
\hline
\end{tabular}

Further correlation analysis between FFE score and children's FNL score showed similar results, the scores of total FFE, dimensions of family sociodemographic characteristics, caregiver's FNL, family eating rules, and family food availability were positively related with children's FNL score, as shown in Table 4. The total FFE and caregiver's FNL scores were positively related with children's FNL scores of different domains and dimensions $(P<0.05)$. The "family eating rules" score was positively related with children's FNL scores of cognitive and total skill domains $(P<0.05)$. The "family food availability" score was positively related with children's FNL scores of "access and planning of food" dimension $(P<0.05)$. The higher "family sociodemographic characteristics" score was significantly related with higher "preparing food", "eating" scores of children $(P<0.05)$. The dimensions of "family feeding patterns" and "family meal practices" were not related with children's FNL score $(P>0.05)$. 
Table 4

Correlation coefficient between family food environment score and food and nutrition literacy score in children $(n=260)$

\begin{tabular}{|c|c|c|c|c|c|c|c|c|c|c|c|c|c|c|c|c|}
\hline \multirow{3}{*}{$\begin{array}{l}\text { Family food } \\
\text { environment } \\
\text { scores }\end{array}$} & \multirow[t]{2}{*}{ Total } & & & \multicolumn{3}{|c|}{$\begin{array}{l}\text { Cognitive } \\
\text { domain }\end{array}$} & \multicolumn{10}{|c|}{ Skill domain } \\
\hline & & & & \multicolumn{2}{|c|}{$\begin{array}{l}\text { Knowledge } \\
\text { Understanding }\end{array}$} & & \multicolumn{2}{|l|}{ Total } & \multicolumn{2}{|c|}{$\begin{array}{l}\text { Access } \\
\text { and } \\
\text { planning } \\
\text { of food }\end{array}$} & \multicolumn{3}{|c|}{$\begin{array}{l}\text { Selecting } \\
\text { food }\end{array}$} & \multicolumn{3}{|c|}{$\begin{array}{l}\text { Preparing } \\
\text { food }\end{array}$} \\
\hline & $P$ & & $r$ & $P$ & & $r$ & $P$ & $r$ & $P$ & & $r$ & $P$ & & $r$ & $P$ & \\
\hline Total & 0.265 & ¿. $001 *$ & & 0.221 & $\begin{array}{l}<.001 * \\
0.00\end{array}$ & & 0.249 & $\begin{array}{l}<.001 * \\
0.00\end{array}$ & 0.184 & $0.003^{*}$ & & 0.189 & $0.002^{*}$ & & 0.084 & 0.18 \\
\hline $\begin{array}{l}\text { Family } \\
\text { sociodemographic } \\
\text { characteristics }\end{array}$ & 0.139 & $0.03 *$ & & 0.026 & 0.67 & & 0.158 & $0.01 *$ & 0.023 & 0.71 & & 0.082 & 0.19 & & 0.163 & $0.009 *$ \\
\hline Caregiver's FNL & 0.287 & <. $001 *$ & & 0.301 & <. $001 *$ & & 0.250 & <. $001 *$ & 0.155 & $0.012^{*}$ & & 0.225 & ¿. $001 *$ & & 0.067 & 0.29 \\
\hline $\begin{array}{l}\text { Family feeding } \\
\text { patterns }\end{array}$ & 0.029 & 0.64 & & -0.001 & 0.99 & & 0.035 & 0.58 & -0.022 & 0.72 & & 0.032 & 0.61 & & -0.011 & 0.86 \\
\hline $\begin{array}{l}\text { Family eating } \\
\text { rules }\end{array}$ & 0.144 & $0.02 *$ & & 0.162 & $0.009 *$ & & 0.122 & $0.05^{\star}$ & 0.164 & $0.008 *$ & & 0.102 & 0.10 & & -0.019 & 0.76 \\
\hline $\begin{array}{l}\text { Family meal } \\
\text { practices }\end{array}$ & 0.019 & 0.76 & & -0.060 & 0.34 & & 0.042 & 0.50 & 0.031 & 0.62 & & 0.064 & 0.30 & & -0.038 & 0.54 \\
\hline $\begin{array}{l}\text { Family food } \\
\text { availability }\end{array}$ & 0.122 & $0.05^{*}$ & & 0.109 & 0.08 & & 0.113 & 0.07 & 0.124 & $0.05^{*}$ & & 0.036 & 0.56 & & 0.105 & 0.09 \\
\hline
\end{tabular}

$\mathrm{FNL}=$ food and nutrition literacy, ${ }^{*} P<0.05$, Statistical test used correlation analysis.

\section{Multivariable analysis}

To analyze the relations of FFE with children's FNL generally, the multivariate linear regression analysis showed that the children's FNL score was associated with caregivers and their educational level and FNL score. The children cared dominantly by their father, had higher total and skill domain FNL scores $(P=$ $0.04)$, compared with those cared by the mother. The children's total FNL $(\beta=0.210, P=0.002)$ cognitive $(\beta=0.263, P<0.001)$ and skill $(\beta=0.170, P=0.01)$ domain scores were positively related with the caregivers' FNL, and the cognitive domain score was also positively related with the caregivers' educational level $(\beta=0.139, P=0.04)$. The details were showed in Table 5 .

Table 5

Multivariable analysis of food and nutrition literacy in children $(n=260)$

\begin{tabular}{|c|c|c|c|c|c|c|c|c|c|}
\hline \multirow[t]{2}{*}{ Variables } & \multicolumn{3}{|l|}{ Total } & \multicolumn{3}{|c|}{ Cognitive domain } & \multicolumn{3}{|c|}{ Skill domain } \\
\hline & $\beta$ & $95 \% \mathrm{Cl}$ & $P$ & $\beta$ & $95 \% \mathrm{Cl}$ & $P$ & $\beta$ & $95 \% \mathrm{Cl}$ & $P$ \\
\hline Gender & -0.083 & $(-4.144,0.732)$ & 0.17 & -0.098 & $(-1.162,0.117)$ & 0.11 & -0.069 & $(-3.232,0.864)$ & 0.26 \\
\hline Grade & 0.083 & $(-0.498,2.683)$ & 0.18 & 0.078 & $(-0.152,0.683)$ & 0.21 & 0.075 & $(-0.509,2.164)$ & 0.22 \\
\hline Only child & 0.065 & $(-1.314,3.982)$ & 0.32 & 0.046 & $(-0.452,0.938)$ & 0.49 & 0.064 & $(-1.134,3.316)$ & 0.34 \\
\hline Family economic status & 0.013 & $(-1.811,2.228)$ & 0.84 & -0.103 & $(-0.965,0.094)$ & 0.11 & 0.047 & $(-1.052,2.340)$ & 0.46 \\
\hline Caregiver & -0.123 & $(-5.442,-0.105)$ & $0.04^{\star}$ & -0.021 & $(-0.820,0.580)$ & 0.74 & -0.141 & $(-4.896,-0.412)$ & $0.02 *$ \\
\hline Caregiver's educational level & 0.131 & $(-0.037,5.403)$ & 0.05 & 0.055 & $(-0.419,1.008)$ & 0.42 & 0.139 & $(0.103,4.673)$ & $0.04^{*}$ \\
\hline Caregiver's FNL score & 0.210 & $(0.289,1.211)$ & $0.002^{*}$ & 0.263 & $(0.122,0.364)$ & $<0.001 *$ & 0.170 & $(0.119,0.894)$ & $0.01 *$ \\
\hline Family feeding patterns score & -0.001 & $(-0.854,0.845)$ & 0.99 & -0.026 & $(-0.268,0.177)$ & 0.69 & 0.007 & $(-0.673,0.755)$ & 0.91 \\
\hline Family eating rules score & 0.057 & $(-0.207,0.514)$ & 0.40 & 0.096 & $(-0.028,0.162)$ & 0.16 & 0.039 & $(-0.216,0.389)$ & 0.57 \\
\hline Family eating practices score & 0.015 & $(-0.724,0.924)$ & 0.81 & -0.075 & $(-0.350,0.082)$ & 0.22 & 0.041 & $(-0.458,0.927)$ & 0.51 \\
\hline Family food availability score & 0.025 & $(-0.520,0.762)$ & 0.71 & -0.005 & $(-0.174,0.162)$ & 0.94 & 0.031 & $(-0.411,0.666)$ & 0.64 \\
\hline
\end{tabular}

In the subgroup of grade $3-5,37.7 \%$ of children were overweight or obesity. To further analyze the relations of FFE with overweight risk in children, the multivariate logistic regression analysis showed the children with higher level of caregiver's FNL were less likely to be overweight or obesity $(\mathrm{OR}=0.043$, 95\% Cl: 0.292-0.981, $P=0.04)$, as shown in Table 6. 
Table 6

Relations of family food environment and children's food and nutrition literacy with overweight risk in children $(n=260)$

\begin{tabular}{|c|c|c|c|c|c|c|}
\hline Variables & B & SE & $\chi 2$ & $P$ & OR & $95 \% \mathrm{Cl}$ \\
\hline \multicolumn{7}{|l|}{ Gender } \\
\hline Girl & Reference & & & & & \\
\hline Boy & 0.638 & 0.278 & 5.266 & $0.02^{*}$ & 1.892 & $(1.098,3.262)$ \\
\hline \multicolumn{7}{|l|}{ Grade } \\
\hline 3 & Reference & & & & & \\
\hline 4 & -0.167 & 0.371 & 0.203 & 0.65 & 0.846 & $(0.409,1.750)$ \\
\hline 5 & -0.416 & 0.364 & 1.307 & 0.25 & 0.660 & $(0.323,1.346)$ \\
\hline \multicolumn{7}{|l|}{ Only child } \\
\hline No & Reference & & & & & \\
\hline Yes & -0.518 & 0.292 & 3.135 & 0.08 & 0.596 & $(0.336,1.057)$ \\
\hline \multicolumn{7}{|l|}{ Children's FNL } \\
\hline Low $(<60)$ & Reference & & & & & \\
\hline $\operatorname{High}(\geq 60)$ & 0.110 & 0.307 & 0.128 & 0.72 & 1.116 & $(0.611,2.039)$ \\
\hline \multicolumn{7}{|l|}{ Caregiver } \\
\hline Father & Reference & & & & & \\
\hline Mother & 0.145 & 0.310 & 0.219 & 0.64 & 1.156 & $(0.629,2.125)$ \\
\hline \multicolumn{7}{|l|}{ Family economic status } \\
\hline Poor & Reference & & & & & \\
\hline Medium & 0.670 & 0.511 & 1.714 & 0.19 & 1.953 & $(0.717,5.322)$ \\
\hline Affluent & 0.307 & 0.533 & 0.333 & 0.56 & 1.360 & $(0.479,3.863)$ \\
\hline \multicolumn{7}{|c|}{ Caregiver's educational level } \\
\hline$\leq$ High school & Reference & & & & & \\
\hline$\geq$ Junior college & 0.333 & 0.310 & 1.154 & 0.28 & 1.395 & $(0.760,2.560)$ \\
\hline \multicolumn{7}{|l|}{ Caregiver's FNL } \\
\hline Low $(<12.0)$ & Reference & & & & & \\
\hline High $(\geq 12.0)$ & -0.626 & 0.309 & 4.088 & $0.04^{*}$ & 0.535 & $(0.292,0.981)$ \\
\hline \multicolumn{7}{|l|}{ Family feeding patterns } \\
\hline Enforcement $(<5.6)$ & Reference & & & & & \\
\hline Restriction (5.6 8.4) & 0.704 & 0.467 & 2.271 & 0.13 & 2.022 & $(0.809,5.051)$ \\
\hline Permission ( $\geq 8.4$ ) & 0.212 & 0.342 & 0.383 & 0.54 & 1.236 & $(0.632,2.416)$ \\
\hline \multicolumn{7}{|l|}{ Family eating rules } \\
\hline Low $(<10.8)$ & Reference & & & & & \\
\hline High $(\geq 10.8)$ & 0.088 & 0.310 & 0.082 & 0.78 & 1.093 & $(0.595,2.005)$ \\
\hline \multicolumn{7}{|l|}{ Family meal practices } \\
\hline Poor $(<4.8)$ & Reference & & & & & \\
\hline Good ( $\geq 4.8)$ & -0.154 & 0.289 & 0.284 & 0.59 & 0.857 & $(0.486,1.511)$ \\
\hline \multicolumn{7}{|l|}{ Family food Availability } \\
\hline Unhealthy $(<9.6)$ & Reference & & & & & \\
\hline Healthy ( $\geq 9.6$ ) & -0.168 & 0.315 & 0.284 & 0.59 & 0.845 & $(0.456,1.568)$ \\
\hline
\end{tabular}




\section{Discussion}

Children's food choices and dietary quality depend on the interaction of individual characteristics and contextual environmental factors [20]. This study investigated the relation of FFE with FNL in Chinese school-age children, the results showed family caregivers and their educational level and nutrition literacy, were significantly related with children's FNL and overweight risk.

Most of children's eating behaviors occur with families in and around home, so family food environment is the most relevant contextual factor and focused increasingly. Several models have been proposed to conceptualize the FFE [6; 20;25], overlapping constructs within these models are the basis for our developed conceptual framework of FFEQ-SC, including physical environment (healthy/unhealthy food availability), sociocultural environment (such as caregiver's FNL, family feeding patterns, meal practices, and eating rules), and family sociodemographic characteristics (family caregiver and their educational level). The results of the study showed overall $68.9 \%$ of the children's families had a higher level of total FFE ( $\geq P_{60}$ of total score), among those dimensions, most of the family caregivers were children's mother $(71.4 \%)$ or father $(27.1 \%)$, more families restricted $(61.3 \%)$ or enforced $(20.2 \%)$ their children to eat or not to eat certain foods than permissive pattern (18.5\%), most of the families had eating rules (65.3\%) and good meal practices (68.9\%), and 78.2\% of the families supplied their children more healthy foods than unhealthy foods. Because of the differences of FFE model and assessment instrument, the FFE factors could not be compared directly among studies. A cross-sectional survey in 396 parents of 3 to 5 year-old children of Australia showed the majority of families (87\%) ate most meals at a table, $59 \%$ of parents restricted dessert when their child did not eat dinner, $29 \%$ rewarded their child with dessert for finishing dinner, only $4 \%$ of parents allowed their child to access snacks themselves, fewer than half of those households (39\%) kept both fruit and vegetables in a ready-to-eat, accessible format [31]. An observational cohort study of 699 American children aged 6 to 11 years and their parents showed a high use of encouragement/modeling and restrictive feeding practices and a high availability of low-calorie/nutrient-dense foods in the home, other parenting and food availability measures were near the middle of the possible score range [7]. Above studies draw a consistent conclusion that more families restricted children's eating compared with permission pattern, but the availability of family foods were different, that might be related with other family sociodemographic characteristics and sociocultural factors including family economic status, parent's educational degree, nutritional knowledge and so on.

Undoubtedly, the potential impact of the FFE on children's food choices and diet quality is particularly relevant [12; 13; 15; 16; 22; 30]. A systematic review (14 studies published between 1994 and 2017) indicated family environmental factors (household food availability, caregivers' nutritional knowledge and family income) were consistently associated with children's food consumption and micronutrient intake [21]. But it is noteworthy that behind the dietary behavior and intake, the individual knowledge, skills and behaviors required to plan, manage, select, prepare and eat foods, which is defined as FNL, may play an important role [1; 27]. A cross-sectional study of 101 parent-child dyads showed that for every $1 \%$ increase in Nutrition Literacy Assessment Instrument for Parents (NLitP), there was a 0.51 increase in child diet quality (Healthy Eating Index) [11].Till now few studies focused on the effect of FFE on individual FNL. The study developed a validated and reliable FNLQ-SC to analyze relations of different FFE factors with children's FNL. The results showed that FFE factors, including family sociodemographic characteristics, family caregiver and their educational level and nutrition literacy, family eating rules, and family healthy food availability, were positively related with children's FNL scores. Especially the family caregiver (father), and caregiver's educational level and nutrition literacy, were consistent and significant predictors of children's FNL, including cognitive and skill domains. The FNL assessment of 803 students aged $10-12$ years in Iran also identified significant associations between total FNLIT and parent's education[8]. Among FNL dimensions, the score of children's healthy "eating" was positively related with family caregiver (father), caregiver's educational level and nutrition literacy, family economic status, and eating rules. Systematic review and other studies presented similar results that caregivers' nutritional knowledge, education and family income were consistently associated with children's healthy food consumption and dietary pattern [14; 21; 22]. Our results furtherly showed the children with higher level of caregiver's FNL were less likely to be overweight or obesity $(\mathrm{OR}=0.043,95 \% \mathrm{Cl}: 0.292-0.981, P<0.05)$. These findings highlight the importance of targeting and nutritional knowledge of family caregivers by education to facilitate the capacity of children to obtain, process, and understand nutrition information and skills, which are essential to make appropriate nutrition decisions and maintain a good diet and health in children. Intervention studies also demonstrated that a change in the food environment was associated with a change in children's eating behavior, dietary intake and obesity $[10 ; 19 ; 28 ; 29]$.

In the study there were not significant relations of family feeding patterns and food availability with children's healthy "eating" score, which were presented in other studies [15; 21], Cochrane review showed parents' child-feeding practice may lead to small increases in fruit and vegetable consumption in children [15]. The inconsistency of results might be due to the differences of FFE assessment and dietary investigation methods, which need to be explored furtherly. Also the study did not show any significant relations of family feeding patterns and meal practices with children's FNL, and future research should adopt more rigorous methods to advance the field.

Overall, previous studies focused on the impact of food environment on eating behavior and food choice, this study furtherly explored relations of FFE factors with individual knowledge and skill (FNL) to make appropriate nutrition decisions, the results might help to understand the interplay of contextual factors and personal behaviors among children. The study conclusively showed FFE, especially caregivers and their educational level and nutrition literacy, were significantly related with children's FNL and overweight risk. The findings highlight the importance of targeting nutritional knowledge and skill of family caregivers to facilitate the knowledge and ability of children to plan, select, prepare and eat foods, to maintain a healthy diet and good health.

Considering the limitation of sampling, sample size and confounders control, the food environment and nutrition literacy assessment questionnaires were not widely used, the conclusion of the study should be verified furtherly in another population.

\section{Conclusion}

Family caregivers and their nutritional literacy, were related with children's FNL and overweight risk. These findings highlight the importance of targeting nutritional knowledge of family caregivers to facilitate the children's FNL to maintain good health. However, the conclusion of the study should be verified 
furtherly in another population. Overall, the invention to improve the health of children ought to focus on the whole family, especially their caregivers, not only the child itself.

\section{Abbreviations}

FFE

Family Food Environment; FNL:Food and Nutrition Literacy; FFEQ-SC:Family Food Environment Questionnaire for Chinese School-Age Children; FNLQ-SC:Food and Nutrition Literacy Questionnaire for Chinese School-Age Children; NHANES:American National Health and Nutrition Examination Survey; CHNS:China Health and Nutrition Survey; ANGELO:Analysis Grid for Elements Linked To Obesity; HBSC:Health Behavior in School-Aged Children; GFI:Goodnessof Fit Index; AGFI:Adjusted Goodness of Fit; NFI:Normed Fit Index; IFI:Incremental Fit Index; CFI:Comparative Fit Index; RMR:Root Mean Square Residual; RMSEA:Root Mean Square Error of Approximation; EFA:Exploratory Factor Analysis

\section{Declarations}

\section{Ethics approval and consent to participate}

This study was conducted according to the guidelines laid down in the Declaration of Helsinki and all procedures involving research study participants were approved by the Peking University Institutional Review Board (Beijing, China), IRB00001052-17115. Written informed consent was obtained from all subjects.

\section{Consent for publication}

Not applicable.

\section{Availability of data and materials}

The datasets used and/or analyzed during the current study are available from the corresponding author on reasonable request.

\section{Competing Interests}

None.

Funding

This research was funded by United Nations International Children's Emergency Fund (UNICEF), Num:2300096295.

\section{Authors' contributions}

conceptualization, LNN, SX and ZWL; methodology, LNN, SX and LT; formal analysis, LNN, SJ, LT; writing-original draft preparation, LNN and SX; writingreview and editing, LNN, LT, SJ, ZWL; project administration, ZWL. All authors reviewed and approved the final manuscript.

\section{Acknowledgements}

We are grateful for the support of the primary school in Beijing China, where this study was conducted for a good collaboration during this study. We thank all teammates for their assistance in every procedure. We would also like to acknowledge all children and their family for their participation and support.

\section{Author details}

Department of Nutrition and Food Hygiene, Peking University School of Public Health; National Health Commission Key Laboratory of Reproductive Health, Beijing 100191, China.

\section{References}

1. Azevedo PE, Thomas H, Samra HR, Edmonstone S, Davidson L, Faulkner A, Petermann L, Manafò E, Kirkpatrick SI. Identifying Attributes of Food Literacy: A Scoping Review. PUBLIC HEALTH NUTRITION. 2017;20:2406-15. doi:10.1017/S1368980017001276.

2. Azzopardi PS, Hearps SJC, Francis KL, Kennedy EC, Mokdad AH, Kassebaum NJ, Lim S, Irvine CMS, Vos T, Brown AD, Dogra S, Kinner SA, Kaoma NS, Naguib M, Reavley NJ, Requejo J, Santelli JS, Sawyer SM, Skirbekk V, Temmerman M, Tewhaiti-Smith J, Ward JL, Viner RM, Patton GC. Progress in Adolescent Health and Wellbeing: Tracking 12 Headline Indicators for 195 Countries and Territories, 1990-2016. The Lancet. 2019;393:1101-18. doi:https://doi.org/10.1016/S0140-6736(18)32427-9.

3. Boucher BA, Manafò E, Boddy MR, Roblin L, Truscott R. The Ontario Food and Nutrition Strategy: Identifying Indicators of Food Access and Food Literacy for Early Monitoring of the Food Environment. Health Promot Chronic Dis Prev Can. 2017;37:313-9. doi:10.24095/hpcdp.37.9.06.

4. Bundy DAP, de Silva N, Horton S, Patton GC, Schultz L, Jamison DT, Abubakara A, Ahuja A, Alderman H, Allen N, Appleby L, Aurino E, Azzopardi P, Baird S, Banham L, Behrman J, Benzian H, Bhalotra S, Bhutta Z, Black M, Bloem P, Bonell C, Bradley M, Brinkman S, Brooker S, Burbano C, Burnett N, Cernuschi T, Clarke S, Coffey C, Colenso P, Croke K, Daniels A, De la Cruz E, de Walque D, Deolaikar A, Drake L, Fernald L, Fernandes M, Fernando D, Fink G, Galloway R, Gelli A, Georgiadis A, Gitonga C, Giyosa B, Glewwe P, Gona Nzovu J, Gove A, Graham N, Greenwood B, Grigorenko E, Heath C, Hicks JH, Hidrobo M, Hill K, Hill T, Hollingsworth TD, Kennedy E, Khan I, Kiamba J, Kim J, Kremer M, LaMontagne DS, Lassi Z, Laxminarayan R, Mahon J, Mai L, Martínez S, Meresman 
S, Merseth KA, Miguel E, Mitchell A, Mitra S, Moin A, Mokdad A, Mont D, Nandi A, Nankabirwa J, Plaut D, Pradhan E, Pullan R, Reavley N, Santelli J, Sarr B, Sawyer SM. Investment in Child and Adolescent Health and Development: Key Messages From Disease Control Priorities, 3Rd Edition. The Lancet. 2018;391:687-99. doi:https://doi.org/10.1016/S0140-6736(17)32417-0.

5. Couch SC, Glanz K, Zhou C, Sallis JF, Saelens BE. Home Food Environment in Relation to Children's Diet Quality and Weight Status. Journal of the Academy of Nutrition Dietetics. 2014a;114:1569-79. doi:10.1016/j.jand.2014.05.015.

6. Couch SC, Glanz K, Zhou C, Sallis JF, Saelens BE. Home Food Environment in Relation to Children's Diet Quality and Weight Status. J Acad Nutr Diet. 2014b;114:1569-79. doi:10.1016/j.jand.2014.05.015.

7. Couch SC, Glanz K, Zhou C, Sallis JF, Saelens BE. Home Food Environment in Relation to Children's Diet Quality and Weight Status. Journal of the Academy of Nutrition Dietetics. 2014c;114:1569-79. doi:10.1016/j.jand.2014.05.015.

8. Doustmohammadian A, Keshavarz MN, Omidvar N, Amini M, Abdollahi M, Eini-Zinab H, Amirhamidi Z, Esfandiari S, Nutbeam D. Food and Nutrition Literacy (FNLIT) and its Predictors in Primary Schoolchildren in Iran. HEALTH PROMOTION INTERNATIONAL. 2019;34:1002-13. doi:10.1093/heapro/day050.

9. FAO IUWA. The State of Food Security and Nutrition in the World 2019. Safeguarding Against Economic Slowdowns and Downturns. FAO: Roma; 2019.

10. Gerards SM, Kremers SP. The Role of Food Parenting Skills and the Home Food Environment in Children's Weight Gain and Obesity. Curr Obes Rep. 2015;4:30-6. doi:10.1007/s13679-015-0139-x.

11. Gibbs HD, Kennett AR, Kerling EH, Yu Q, Gajewski B, Ptomey LT, Sullivan DK. Assessing the Nutrition Literacy of Parents and its Relationship with Child Diet Quality. JOURNAL OF NUTRITION EDUCATION AND BEHAVIOR. 2016;48:505-9. doi:10.1016/j.jneb.2016.04.006.

12. $10.3390 /$ nu9020126

Hebestreit A, Intemann T, Siani A, De Henauw S, Eiben G, Kourides YA, Kovacs E, Moreno LA, Veidebaum T, Krogh V, Pala V, Bogl LH, Hunsberger M, Bornhorst C, Pigeot I. (2017). Dietary Patterns of European Children and their Parents in Association with Family Food Environment: Results from the I.Family Study. Nutrients, 9. doi: 10.3390/nu9020126.

13. Hendrie G, Sohonpal G, Lange K, Golley R. Change in the Family Food Environment is Associated with Positive Dietary Change in Children. Int J Behav Nutr Phys Act. 2013;10:4. doi:10.1186/1479-5868-10-4.

14. $10.3390 /$ nu10040436

Hinnig PF, Monteiro JS, de Assis M, Levy RB, Peres MA, Perazi FM, Porporatti AL, Canto GL. (2018). Dietary Patterns of Children and Adolescents from High, Medium and Low Human Development Countries and Associated Socioeconomic Factors: A Systematic Review. Nutrients, 10. doi: 10.3390/nu10040436.

15. Hodder RK, O'Brien KM, Stacey FG, Wyse RJ, Clinton-McHarg T, Tzelepis F, James EL, Bartlem KM, Nathan NK, Sutherland R, Robson E, Yoong SL, Wolfenden L. Interventions for Increasing Fruit and Vegetable Consumption in Children Aged Five Years and Under. Cochrane Database Syst Rev. 2018;5:D8552. doi:10.1002/14651858.CD008552.pub5.

16. Jackson JA, Smit E, Branscum A, Gunter K, Harvey M, Manore MM, John D. The Family Home Environment, Food Insecurity, and Body Mass Index in Rural Children. Health Educ Behav. 2017;44:648-57. doi:10.1177/1090198116684757.

17. Liu D, Zhao LY, Yu DM, Ju LH, Zhang J, Wang JZ, Zhao WH. (2018). Dietary Patterns and Association with Obesity of Children Aged 6(-)17 Years in Medium and Small Cities in China: Findings From the CNHS 2010(-)2012. Nutrients, 11. doi:10.3390/nu11010003.

18. Liu J, Rehm CD, Onopa J, Mozaffarian D. Trends in Diet Quality Among Youth in the United States, 1999-2016. JAMA. 2020;323:1161-74. doi:10.1001/jama.2020.0878.

19. Santiago-Torres M, Adams AK, Carrel AL, LaRowe TL, Schoeller DA. Home Food Availability, Parental Dietary Intake, and Familial Eating Habits Influence the Diet Quality of Urban Hispanic Children. Child Obes. 2014;10:408-15. doi:10.1089/chi.2014.0051.

20. $10.3390 /$ nu10060706

Scaglioni S, De Cosmi V, Ciappolino V, Parazzini F, Brambilla P, Agostoni C. (2018). Factors Influencing Children's Eating Behaviours. Nutrients, 10. doi: 10.3390/nu10060706.

21. Sirasa F, Mitchell LJ, Rigby R, Harris N. Family and Community Factors Shaping the Eating Behaviour of Preschool-Aged Children in Low and MiddleIncome Countries: A Systematic Review of Interventions. PREVENTIVE MEDICINE. 2019;129:105827. doi:10.1016/j.ypmed.2019.105827.

22. Stahlmann K, Hebestreit A, DeHenauw S, Hunsberger M, Kaprio J, Lissner L, Molnar D, Ayala-Marin AM, Reisch LA, Russo P, Tornaritis M, Veidebaum T, Pohlabeln H, Bogl LH. A Cross-Sectional Study of Obesogenic Behaviours and Family Rules According to Family Structure in European Children. Int $\mathrm{J}$ Behav Nutr Phys Act. 2020;17:32. doi:10.1186/s12966-020-00939-2.

23. Sun S, He J, Fan X. (2019). Mapping and Predicting Patterns of Chinese Adolescents' Food Preferences. Nutrients, 11. doi:10.3390/nu11092124.

24. Swinburn B, Egger G, Raza F. Dissecting Obesogenic Environments: The Development and Application of a Framework for Identifying and Prioritizing Environmental Interventions for Obesity. PREVENTIVE MEDICINE. 1999a;29:563-70. doi:10.1006/pmed.1999.0585.

25. Swinburn B, Egger G, Raza F. Dissecting Obesogenic Environments: The Development and Application of a Framework for Identifying and Prioritizing Environmental Interventions for Obesity. PREVENTIVE MEDICINE. 1999b;29:563-70. doi:10.1006/pmed.1999.0585.

26. Vaitkeviciute R, Ball LE, Harris N. The Relationship Between Food Literacy and Dietary Intake in Adolescents: A Systematic Review. PUBLIC HEALTH NUTRITION. 2015;18:649-58. DOI:10.1017/S1368980014000962. doi.

27. Vaitkeviciute R, Ball LE, Harris N. The Relationship Between Food Literacy and Dietary Intake in Adolescents: A Systematic Review. PUBLIC HEALTH NUTRITION. 2015;18:649-58. doi:10.1017/S1368980014000962. 
28. Vargas-Garcia EJ, Evans CEL, Prestwich A, Sykes-Muskett BJ, Hooson J, Cade JE. Interventions to Reduce Consumption of Sugar-Sweetened Beverages Or Increase Water Intake: Evidence From a Systematic Review and Meta-Analysis. Obes Rev. 2017;18:1350-63. doi:10.1111/obr.12580.

29. Vereecken C, Haerens L, De Bourdeaudhuij I, Maes L. The Relationship Between Children's Home Food Environment and Dietary Patterns in Childhood and Adolescence. Public Health Nutr. 2010;13:1729-35. doi:10.1017/s1368980010002296.

30. Wang J, Fielding-Singh P. How Food Rules at Home Influence Independent Adolescent Food Choices. J Adolesc Health. 2018;63:219-26. doi:10.1016/j.jadohealth.2018.02.010.

31. Wyse R, Campbell E, Nathan N, Wolfenden L. Associations Between Characteristics of the Home Food Environment and Fruit and Vegetable Intake in Preschool Children: A Cross-Sectional Study. BMC PUBLIC HEALTH. 2011;11:938. doi:10.1186/1471-2458-11-938.

32. Zhen S, Ma Y, Zhao Z, Yang X, Wen D. Dietary Pattern is Associated with Obesity in Chinese Children and Adolescents: Data From China Health and Nutrition Survey (CHNS). Nutr J. 2018;17:68. doi:10.1186/s12937-018-0372-8. 